\title{
Oestrogen and progestogen receptors in endometrium and myometrium at the time of blastocyst implantation in pregnant diabetic rats
}

\author{
R. De Hertogh, I. Vanderheyden, B. Glorieux and E. Ekka† \\ Physiology of Human Reproduction Research Unit, University of Louvain, School of Medicine, Brussels, Belgium
}

\begin{abstract}
Summary. A suitable hormonal environment is a prerequisite for blastocyst implantation. Experimental diabetes was previously shown to modify the hormonal milieu and produce alterations in oestrogen receptor kinetics in the uterine tissue. In the present work, oestrogen and progestogen receptor levels were measured on the morning of day 6 of pregnancy in normal and in streptozotocin-induced diabetic rats, both in implantation sites and in interembryonic segments of endometrium and myometrium. Receptor levels were different in the implantation sites compared to the interembryonic segments of endometrium, both in the control and in the diabetic animals. Indeed, implantation sites were characterized by lower oestrogen receptor levels in cytosol and higher progestogen receptor levels in cytosol and nuclei. However, compared to the control rats, the diabetic rats had lower oestrogen receptor levels in implantation sites, both in cytosol and nuclei. In the myometrium, the differences between sites or between types
\end{abstract}

of rats were minimal. Plasma levels of oestradiol were lower in diabetic rats than in control animals, whereas progesterone levels were similar. A 20\% lower implantation rate was found in diabetic rats, compared to normal rats. These results show that the specific distribution of oestrogen and progestogen receptors between implantation sites and interembryonic segments was preserved in the diabetic rats; however the absolute level of oestrogen receptor was lower. This abnormal endocrine milieu might arise from a lower oestradiol level and a decreased oestradiol/progesterone ratio in the circulating blood. Whether the lower implantation rate in diabetic rats might be a consequence of the overall disturbed hormonal status remains to be elucidated.

Key words: Blastocyst, implantation, rat, oestrogens, progesterone, receptors, pregnancy, experimental diabetes.
The influence of maternal diabetes on early embryo development and implantation is still largely unknown. Early fetal growth delay has been described in the fetuses of human diabetic patients and this observation has been related to a higher incidence of congenital malformations in this group [1-3]. An increased rate of congenital defects indeed occurs both in clinical [4], and experimentally induced diabetes [5]. Although efficient insulin treatment appears to reduce the rate of malformation $[6,7]$, the nature of the diabetic aggression leading to teratogenesis is not known [5]. Recent developments draw attention to very early steps in embryo development, close to the implantation period, which might be more sensitive to metabolic disturbances [8-10]. The investigation of the embryo-maternal interrelationship around the time of implantation could be an important approach in the understanding of the deleterious effect a metabolically disturbed environment could exert on early embryo development, implantation and further differentiation.
The implantation procedure in the rat begins on the evening of day 5 , continues on day 6 and is completed on day 7 [11]. During that period, hormonal modifications occur at the implantation site leading to specific receptor kinetics [12-15]. In non-pregnant streptozotocin-induced diabetic rats, oestrogen receptors are present at essentially normal concentrations in both the endometrium and myometrium, and oestrogen activity is essentially unchanged [16, 17]. Receptor kinetics may, however, be disturbed due to abnormal oestrogen metabolism in the diabetic animal $[18,19]$, resulting in decreased oestrogen action at the endometrium level [19-20]. Insulin treatment however restores normal receptor kinetics and hormonal activity [21], emphasizing the specificity of these observations.

In the present work, we investigated the oestrogen and progestogen receptor kinetics at the time of implantation, both in normal and diabetic rats. Although results were similar in both the diabetic and the nor- 


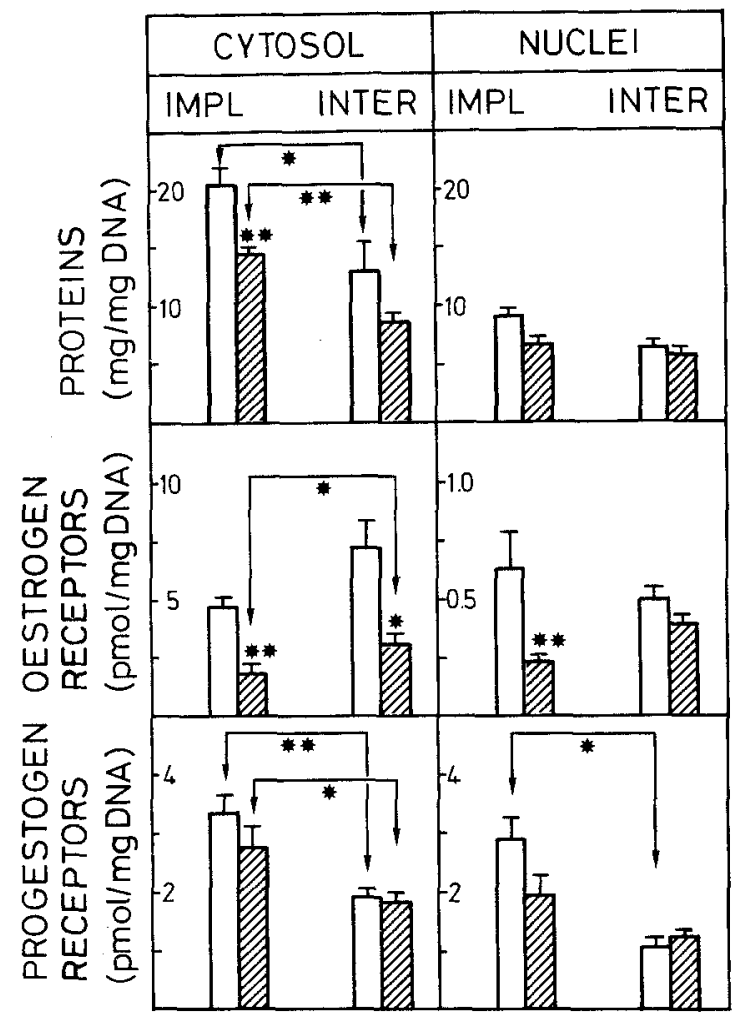

Fig. 1. Oestrogen-receptor, progestogen-receptor and protein levels in subcellular fractions of endometrium in control rats (open bars) and in diabetic rats (hatched bars) on the morning of day 6 of pregnancy. IMPL = Implantation sites; INTER = Interembryonic segments. Statistical significance between IMPL and INTER is shown by the arrows. Significant differences between control and diabetic groups are given on top of the hatched bars. Figures are the means \pm SEM of 6 replicates. Each replicate was performed on pooled sites from 8 to 10 rats. ${ }^{*} p<0.05 * * p<0.01$

mal rats as far as specific receptor distribution at the implantation sites is concerned, the diabetic animals had lower oestrogen receptor levels than the controls mainly at the implantation sites. Diabetic rats also had lower plasma levels of oestradiol and lower oestradiol/progesterone ratios. Finally, a 20\% lower rate of implantation was observed in the diabetic animals.

Table 1. Plasma levels of oestradiol-17 $(\mathrm{OE} 2)$ and progesterone (P) in pregnant rats (mean \pm SD for $n$ animals)

\begin{tabular}{|c|c|c|c|c|c|}
\hline \multicolumn{3}{|l|}{ Day 6} & \multicolumn{3}{|l|}{ Day 7} \\
\hline $\begin{array}{l}\text { OE } 2 \\
(\mathrm{pg} / \mathrm{ml})\end{array}$ & $\begin{array}{l}P \\
(\mathrm{ng} / \mathrm{ml})\end{array}$ & $\begin{array}{l}\text { OE 2/P } \\
\left(\times 10^{3}\right)\end{array}$ & $\begin{array}{l}\text { OE } 2 \\
(\mathrm{pg} / \mathrm{ml})\end{array}$ & $\begin{array}{l}P \\
(\mathrm{ng} / \mathrm{ml})\end{array}$ & $\begin{array}{l}\text { OE 2/P } \\
\left(\times 10^{3}\right)\end{array}$ \\
\hline
\end{tabular}

\begin{tabular}{lrrcrrl}
\hline Control rats & & & & & & \\
$\overline{\mathrm{X}}$ & 18 & 67 & 0.31 & 15 & 59 & 0.25 \\
$\mathrm{SD}$ & 4 & 20 & 0.13 & 3 & 10 & 0.08 \\
$n$ & 16 & 16 & 16 & 5 & 5 & 5 \\
Diabetic rats & & & & & & \\
$\mathrm{X}$ & $14^{\mathrm{b}}$ & 66 & $0.23^{\mathrm{a}}$ & $10^{\mathrm{b}}$ & 65 & $0.16^{\mathrm{b}}$ \\
$\mathrm{SD}$ & 4 & 17 & 0.09 & 3 & 19 & 0.04 \\
$n$ & 23 & 23 & 23 & 14 & 14 & 14 \\
\hline
\end{tabular}

${ }^{\mathrm{a}} p<0.05$ with control rats; ${ }^{\mathrm{b}} p<0.01$ with control rats

\section{Materials and methods}

\begin{abstract}
Animals
Wistar rats from the faculty breeding centre (Universite Catholique de Louvain, Brussels, Belgium) were mated overnight as previously described [13]. The presence of a vaginal plug the next morning was considered as day 1 of pregnancy. On the morning of day 6 (09.00-10.00 hours), $1 \mathrm{ml} 0.5 \%$ Evans blue was injected i.v. The animals were killed 15-20 min later and the implantation sites (well defined blue stripes) and the interembryonic segments collected, and kept separately in liquid nitrogen. Diabetic rats were obtained by injecting streptozotocin $(45 \mathrm{mg} / \mathrm{kg})$ i.v. as previously described $[16,17]$. They were mated with male rats 8 days after the onset of diabetes (blood glucose levels above $20 \mathrm{mmol} / 1$, slight or no ketonuria). If they did not become pregnant, they were mated again 15 and 21 days after streptozotocin injection, to allow a one-week interval between each overnight mating. After three unsuccessful trials, they were discarded from the experimental group.
\end{abstract}

\section{Methods}

All the methods for oestrogen and progestogen receptor measurements have been described previously [13]. Protein and DNA measurements have also been reported earlier [13].

Progesterone and oestradiol-17 $\beta$ were measured in individual plasma samples collected at the time the animals were killed. Classic routine radioimmunoassay techniques were used (Ire Medgenix, Fleurus, Belgium). However, plasma samples were first extracted with ether, and the extracts washed with distilled water, to remove the Evans blue contaminating the sample.

\section{Statistical analysis}

Statistical significance between implantation sites and interembryonic segments was determined with the two tailed paired Student's $t$ test. Difference between control and diabetic rats was analysed with the two tailed unpaired Student's $t$ test. The level for a statistically significant difference was set at $p<0.05$.

\section{Results}

\section{Protein concentrations}

In the endometrium (Fig.1) protein levels were higher in the cytosol of implantation sites, when compared to interembryonic segments, both in the normal and in the diabetic animals. Diabetic rats had a lower protein concentration in cytosol of implantation sites when compared to the normal animals.

In the myometrium (Fig. 2) protein concentrations were higher in the cytosol of implantation sites in both control and diabetic rat tissue. Diabetic animals had lower nuclear protein levels than the normal rats.

\section{Oestrogen receptor levels}

In the endometrium (Fig.1), oestrogen receptor levels were lower in the cytosol of implantation sites, compared to interembryonic segments. This difference 
reached statistical significance in the diabetic but not in the control rats. Lower oestrogen receptor levels were observed in the cytosol of both uterine segments as well as in the nuclei of implantation sites of diabetic compared to normal rats.

In the myometrium (Fig.2) no difference was observed between uterine segments, in neither the control nor in the diabetic rats. Diabetic animals had slightly higher levels as compared to control rats in interembryonic segments.

\section{Progestogen receptors}

In the endometrium (Fig.1), progestogen receptor levels were higher in implantation sites, when compared to interembryonic segments, both in the cytosol and nuclei, of normal and diabetic rats. Progestogen receptor levels in implantation sites of the diabetic rats were slightly (not significantly) lower than in the normal rats. In the myometrium, diabetic rats had similar levels of progestogen receptors to the normal animals.

\section{Oestradiol and Progesterone plasma levels}

Table 1 shows that oestradiol plasma levels were significantly lower in the diabetic rats compared to the control animals, both on day 6 and day 7 . Progesterone levels were the same. Oestradiol/Progesterone ratios were lower in diabetic animals.

\section{Implantation rate}

Table 2 gives the mean implantation number per rat in normal rats on days 5, 6 and 7 and in diabetic animals on days 6 and 7. The mean number of sites increased about $15 \%$ from day 5 to day 6 , and remained unchanged on day 7. Diabetic rats had a $20 \%$ lower implantation rate as compared to the corresponding controls.

\section{Discussion}

Blastocyst implantation requires an adequate oestrogen-progesterone milieu [11]. Hence, an oestrogen surge is needed to initiate the endometrium receptivity period, during which implantation would be accepted [22-23]. The blastocyst itself most likely contributes to the hormonal mechanisms leading to its own implantation [24]. In some species, oestrogens are produced by the blastocyst, which might then implant without any maternal oestrogen surge [25]. In the rat, such hormonal contributions from the blastocyst have been debated, but not proven [13].

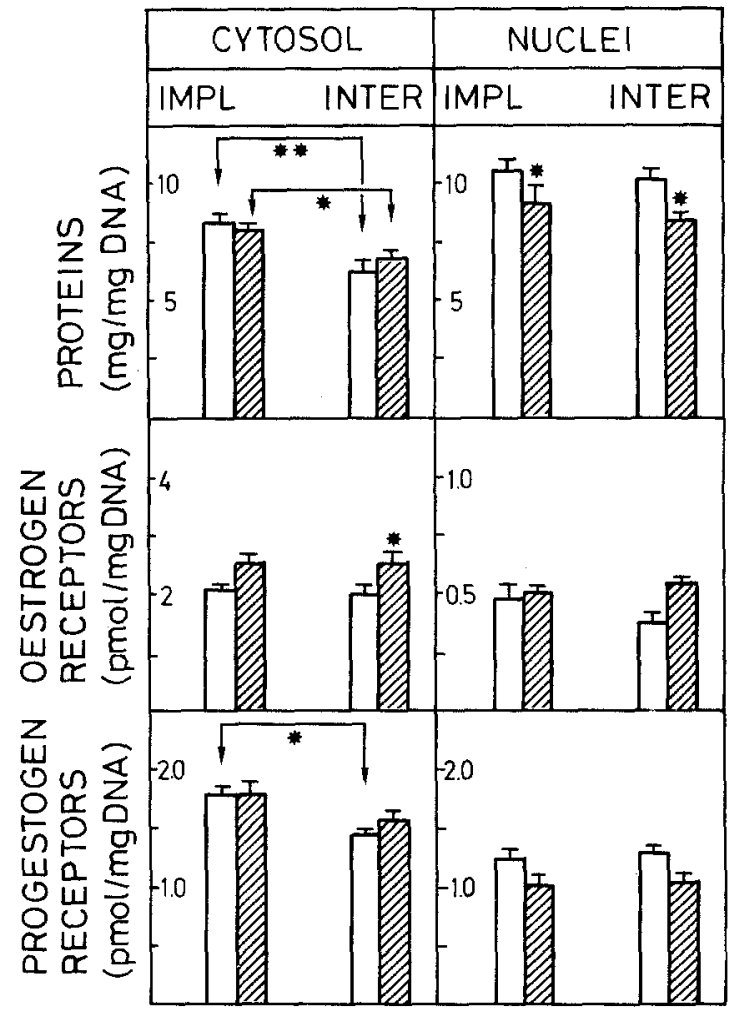

Fig.2. Oestradiol-receptor, progesterone-receptor and protein levels in subcellular fractions of myometrium in control rats (open bars) and in diabetic rats (hatched bars) on the morning of day 6 of pregnancy. IMPL = Implantation sites; INTER $=$ Interembryonic segments. Statistical significance between IMPL and INTER is shown by the arrows. Significant differences between control and diabetic groups are given on top of the hatched bars. Figures are the means \pm SEM of 6 replicates. Each replicate was performed on pooled sites from 8 to 10 rats. $* p<0.05 * * p<0.01$

Specific modifications of receptor distributions were described at the implantation sites, where oestrogen receptor levels decreased in the cytosol but not in the nuclei, whereas progestogen receptor levels increased in both fractions between the evening of day 5 and the morning of day 6 of pregnancy [12-15]. These modifications could result from a local oestrogenic effect on receptor kinetics [26-28] and synthesis [29], although the origin and the nature of the oestrogen effector remains unsettled. Nevertheless, a similar oestrogenic effect was observed in the present study of diabetic rats (lower oestrogen and higher progestogen receptor levels in implantation sites, compared

Table 2. Number of implantation sites per rat

\begin{tabular}{lll}
\hline & Control rats & Diabetic rats \\
\hline Day 5 & $8.91 \pm 3.34^{\mathrm{a}}$ & - \\
& $(141)^{\mathrm{b}}$ & \\
Day 6 & $10.4 \pm 3.18^{\mathrm{c}}$ & $8.2 \pm 3.19^{\mathrm{d}}$ \\
& $(327)$ & $(137)$ \\
Day 7 & $9.9 \pm 2.7$ & $8.0 \pm 3.3$ \\
& $(14)$ & $(18)$ \\
\hline
\end{tabular}

${ }^{\mathrm{a}}$ Mean $\pm \mathrm{SD} ;{ }^{\mathrm{b}}$ Number of rats; ${ }^{\mathrm{c}} p<0.001$ with Day $5 ;{ }^{\mathrm{d}} p<0.001$ with control rats 
to interembryonic segments). Earlier work has shown that oestrogen receptor kinetics were essentially normal in non-pregnant diabetic rats $[16,17]$. Also, oestrogens were able to stimulate progestogen receptor synthesis in diabetic as well as in non-diabetic ovariectomized rats [30]. A similar conclusion can be drawn from the present study in diabetic pregnant animals.

However, the striking observation reported here, is the lower levels of cytosol and nuclear oestrogen receptors in implantation sites of the diabetic rats compared to the control animals. This situation is important, since it implies a potentially disturbed hormonal environment at the site where the implanted blastocyst is likely to interact with the uterine bed. Decreased oestrogen [31-33] and corticosterone [34] receptor levels have been reported in the central nervous system, and decreased androgen receptor levels [35] in the prostate of diabetic rats. However, in uterine tissues of non-pregnant rats, normal oestrogen and progesterone receptor levels were found, from a few days up to several months after onset of diabetes, despite loss of weight and progressive catabolic state $[16,17,30]$. The cause of the decreased oestrogen receptor levels in implantation sites of diabetic rats is not known. Several hypotheses can be proposed. Time delayed receptor kinetics seem unlikely, since oestrogen receptor levels were shown to decrease, and not increase in implantation sites of normal rats from day 5 to day $6[14,15]$. It is also unlikely that streptozotocin might, on its own, induce such specific alteration, predominantly in implantation sites, 2 to 4 weeks after injection. Although long-lasting damage to some tissue function is possible, previous works performed in non-pregnant rats have shown that oestrogen receptor levels were not altered in streptozotocin induced diabetic animals, indicating a lack of effect of streptozotocin itself on the expression of these receptors $[16,17]$. Moreover, the abnormal receptor kinetics obtained after i.p. administration of oestradiol were fully reversed by insulin treatment [21]. Hormonal activity on uterine protein synthesis was also restored to normal [21].

One might thus speculate that diabetes induced disturbed receptor kinetics might occur in pregnant rats, and result in lower oestrogen receptor levels in the early days of pregnancy predominantly at the implantation sites, where a specific oestrogenic effect is expected. As shown in non-pregnant rats, experimental diabetes increases the oestradiol clearance rate [18], which in turn may disturb the subcellular kinetics of oestrogen receptors in the uterine tissue [19]. We observed a lower plasma oestradiol level in the pregnant diabetic rats, which is likely to result from increased metabolism of the hormone (18 and unpublished observations), and not from decreased luteal function as described in pseudo-pregnant diabetic rats [36]. Indeed, progesterone plasma levels were normal in our diabetic pregnant animals. Hence, oestradiol/progesterone ratio was decreased, which adds another hormonal disequilibrium, in favour of progesterone which exerts an inhibitory activity on oestradiol receptor synthesis [37].

Decreased implantation rates in the diabetic rats have not been reported previously. Hormonal imbalance at the implantation site could change uterine receptivity to the preimplantation blastocyst [11]. However, the migration time of the embryo in the genital tract is also dependent on local or systemic hormonal equilibrium between oestradiol and progesterone $[38,39]$. The decreased circulating oestradiol/progesterone ratio observed in the pregnant diabetic rats could slow down this migration speed and delay implantation. Our data do not support this hypothesis; indeed, the implantation rate was not higher on day 7 , remaining $20 \%$ lower in the diabetic animals than in controls.

Other, as yet unknown, factors linked with the diabetic environment of the mother might also be deleterious to the development of the embryo and/or to the receptivity of the endometrial bed [36].

It has been recently reported that two-cell embryos from diabetic mice undergo a slower development in vitro than two-cell embryos from normal mice [40]. This observation and the present study emphasize the need for further study on the early development of embryos from diabetic animals.

In conclusion, the present study, performed in normal and in diabetic rats, showed that an oestrogenic effect was observable at the sites of blastocyst implantation, both in normal and in diabetic animals, although the level of oestrogen receptors was lower in the latter group. A lower oestradiol/progesterone ratio in plasma of diabetic rats could play a role in the disturbed receptor levels. On the other hand, a $20 \%$ lower rate of implantation in the diabetic group, could in some way be the consequence of a disturbed hormonal environment, although other unknown maternal and/or embryological factors may contribute.

Acknowledgments. This work was supported by grants No 3.4528 .33 and 3.4590.88 of the Fonds de la Recherche Scientifique Médicale of Belgium.

\section{References}

1. Pedersen JF, Mølsted-Pedersen L (1981) Early growth delay detected by ultrasound marks increased risk for congenital malformation in diabetic pregnancy. Br Med J 283: 269-271

2. Spiers PS (1982) Does growth retardation predispose the fetus to congenital malformation? Lancet I: 312-314

3. Wilson GN, Howe M, Stover JM (1985) Delayed developmental sequences in rodents diabetic embryopathy. Ped Res 19: 1337-1340

4. Pedersen J (1977) The pregnant diabetic and her newborn (2nd edn). Munksgaard, Copenhagen, pp 1-280

5. Eriksson U (1984) Congenital malformations in diabetic animal models-A review. Diab Res 1: 57-66

6. Fuhrmann K, Reiher H, Semmler K, Fisher F, Fisher M, Glöckner $E$ (1983) Prevention of congenital malformations in infants of insulin-dependent diabetic mothers. Diab Care 6:219-223 
7. Baker L, Egler JM, Klein SH, Goldman AS (1981) Meticulous control of diabetes during organogenesis prevents congenital lumbosacral defects in rats. Diabetes 30:955 959

8. Eriksson UJ, Dahlström E, Hellerström C (1983) Diabetes in pregnancy: skeletal malformations in the offspring of diabetic rats after intermittent withdrawal of insulin in early gestation. Diabetes 32: 1141-1145

9. Freinkel N, Lewis NJ, Akazawa S, Roth SI, Gorman L (1984) The honeybee syndrome. Implication of the teratogenicity of mannose in rat-embryo culture. N Engl J Med 310: 223-230

10. Buchanan TA, Freinkel N (1988) Fuel-mediated teratogenesis; symetric growth retardation in the rat fetus at term after a circumscribed exposure to D-mannose during organogenesis. Am J Obst Gynecol 158: 663-669

11. Psychoyos A (1973) Hormonal control of ovoimplantation. Vitam Horm 31: 201-256

12. Logeat F, Sartor P, Mai Thu Vu Hai, Milgrom E (1980) Local effect of blastocyst on estrogen and progesterone receptors in the rat endometrium. Science 207: 1083-1085

13. De Hertogh R, Ekka E, Vanderheyden I, Glorieux B (1986) Estrogen and progestogen receptors in the implantation sites and interembryonic segments of rat uterus endometrium and myometrium. Endocrinology 119: 680-684

14. De Hertogh R, Vanderheyden I, Ekka E, Glorieux B (1988) Estrogen and progesterone receptor kinetics in normal and diabetic rat uterus at the time of blastocyst implantation. 70th Annual Meeting of the Endocrine Society, New Orleans (USA). Congress Proceedings: 164 (Abstract)

15. Ekka E, Vanderheyden I, Glorieux B, De Hertogh R (1987) Estrogen and progesterone receptor kinetics in rat endometrium and myometrium during the implantation period, suggesting local estrogenic activity at the implantation site. Exp Clin Endocrinol (Life Sci AW) 6: 137-140

16. Ekka E, Vanderheyden I, De Hertogh R (1981) Oestrogen receptors and oestrogen induced protein synthesis in the uterus of diabetic rats. Diabetologia 20: $578-582$

17. De Hertogh R, Ekka E, Vanderheyden I (1982) Estrogen receptor and stimulation of uterine protein synthesis in ovariectomized diabetic rats, intravenously infused with $17-\beta$ estradiol. Endocrinology 110: 741-748

18. De Hertogh R, Vanderheyden I, Delait AM, Ekka E (1984) Enhanced metabolism of $2,4,6,7^{3} \mathrm{H}$ estradiol-17 $\beta$ in the diabetic rat. J Steroid Biochem 21: 433-438

19. Ekka E, Vanderheyden I, De Hertogh R (1982) Short term nuclear retention and early cytosol replenishment of estradiol receptors in uteri of ovariectomized diabetic rats after intraperitoneal injection of 17- $\beta$ estradiol: evidence for decreased hormonal activity on protein synthesis. Endocrinology 111: 456-461

20. Kirkland JL, Barrett GN, Stancel GM (1981) Decreased cell division of the uterine luminal epithelium of diabetic rats in response to $17-\beta$ estradiol. Endocrinology 109: 316-318

21. Ekka E, Vanderheyden I, De Hertogh R (1984) Normalization of estradiol receptor kinetics and hormonal activity in uterus of streptozotocin induced diabetic rats treated with insulin. Endocrinology 114: 2271-2275

22. Yoshinaga K, Hawkins RA, Stocker JF (1969) Estrogen secretion by the rat ovary in vivo during the estrous cycle and pregnancy. Endocrinology 85 : 103-112

23. McCormack JT, Greenwald GS (1974) Evidence for a preimplantation rise in oestradiol-17 $\beta$ levels on day 4 of pregnancy in the mouse. J Reprod Fertil 41: 297-301

24. Dickmann Z, Dey SK, Sengupta J (1976) A new concept: control of early pregnancy by steroid hormones originating in the preimplantation embryo. Vitam Horm 34: 215-242
25. Gadsby JE, Heap RB, Burton RD (1980) Oestrogen production by blastocyst and early embryonic tissue of various species. $\mathrm{J}$ Reprod Fertil 60: 409-417

26. Gorski J, Welshons W, Sakai D (1984) Remodeling the estrogen receptor model. Mol Cell Endocrinol 36:11-15

27. Ekka E, Vanderheyden I, De Hertogh R (1986) Non-stoichiometric nuclear-cytoplasmic redistribution of estrogen receptor in adult rat uterus following estradiol injection. J Steroid Biochem 24: $475-479$

28. Sato B, Nishizawa Y, Noma K, Kishimoto S, Matsumoto K (1983) Chronic estrogen treatment causes an alteration in uterine estrogen receptor dynamics of rats. Biochem Biophys Acta 755: $412-419$

29. Milgrom E, Thi L, Atger M, Beaulieu EE (1973) Mechanisms regulating the concentration and the conformation of progesterone receptor(s) in the uterus. J Biol Chem 248: 6366-6374

30. Ekka E, Vanderheyden I, Glorieux B, De Hertogh R (1987) Estradiol-induced progesterone receptor synthesis in normal and diabetic ovariectomized rat uterus. J Steroid Biochem 28: 61-64

31. Denari JH, Rosner JM (1972) Sexual steroid uptake in the alloxanized diabetic rat. Steroid Lipid Res 3: 151-155

32. Gentry RT, Wade GN, Blaustein JD (1977) Binding of ${ }^{3} \mathrm{H}$-estradiol by brain cell nuclei and female rat sexual behavior: inhibition by experimental diabetes. Brain Res 130: 135-146

33. Coirini H, Weisenberg L, Tornello S, Denicola AF (1980) Effect of experimental diabetes on estradiol binding by the anterior pituitary and hypothalamus in ovariectomized rats. Experientia 36: $683-685$

34. Fridman O, Foglia VG, De Nicola AF (1978) Reduction in ${ }^{3} \mathrm{H}-$ corticosterone binding to cytoplasmic receptors in the brain of diabetic rats. J Steroid Biochem 9:609-614

35. Tesone M, Oliveira-Filho RM, Biella De Souza Valle L, Calvo JC, Baranao JLS, Foglia VG, Charreau EH (1980) Androgen receptors in the diabetic rat. Diabetologia $18: 385-390$

36. Garris DR (1988) Effect of diabetes on uterine condition, decidualization, vascularization, and corpus luteum function in the pseudopregnant rat. Endocrinology 122: 665-672

37. Leavitt WW, Okulicz WC (1985) Progesterone control of nuclear estrogen receptor: demonstration in hamster uterus during the estrous cycle and pseudopregnancy using a new exchange assay. $\mathrm{J}$ Steroid Biochem 22: 583-588

38. Forcelledo ML, Vera R, Croxatto HB (1981) Ovum transport in pregnant, pseudopregnant and cyclic rats and its relationship to estradiol and progesterone blood levels. Biol Reprod 24: 760-765

39. Fuentealba B, Nieto M, Croxatto HB (1987) Ovum transport in pregnant rats is little affected by RU 486 and exogenous progesterone as compared to cycling rats. Biol Reprod 37: 768-774

40. Moley KH, Diamond MP, Pellicer A, Vaughn WK, De Cherney AH (1988) Impaired in vitro development of preimplantation mouse embryos from alloxan and streptozotocin diabetic mice, and resolution by maternal in vivo insulin therapy. American Diabetic Association Meeting, New-Orleans. Diabetes 37 [Suppl 1]: 86A (Abstract)

Received: 8 December 1988

and in revised form: 25 April 1989

Dr. R. De Hertogh

Physiology of Human Reproduction Research Unit

University of Louvain

Avenue E. Mounier, 53, U.C. L. 5330

B-1200 Brussels

Belgium 